\title{
Towards a means of consistently comparing airline business models with an application to the 'low cost' airline sector
}

\author{
Keith J. Mason* \\ William G. Morrison** \\ *Senior Lecturer, Dept of Air Transport, Cranfield University, UK. \\ Corresponding author \\ K.mason@cranfield.ac.uk \\ Tel: +44 1234754233 \\ Fax: +44 1234720532 \\ ** Associate Professor, School of Business and Economics, \\ Wilfrid Laurier University, Waterloo, Canada. wmorrison@wlu.ca
}

April 2008

\begin{abstract}
Meaningful definitions of and distinctions between airline business models are not easily formulated, particularly when one considers the extremely dynamic nature of the industry. The paper outlines a product and organizational architecture (POA) approach to classifying and relating key elements of airline business models. Using indices to create benchmark metrics, the POA model is then used to examine and compare six European airlines. The analysis shows that there are important differences in the business models of airlines who are all commonly referred to as 'low cost carriers'. The paper demonstrates how differences in the business models adopted by the different airlines contribute to their relative profitability.
\end{abstract}

Keywords: Low cost carrier; product and organizational architecture; airline business models. 


\section{Introduction}

Much has been written about the low cost airline business model and what elements in the business model distinguish it from traditional full service airlines. Williams and Mason (2004) reviewed the group of strategies that together enable low cost carriers to exercise cost advantages over full service airlines (p.8) (see also Francis, et.al, 2003). The review highlighted significant differences between low cost carriers in their business models. For some carriers it is not clear if they should be called "low cost carrier", "regional carrier", or some other term. When comparing airline performance it is useful to compare one airline with others of a similar business approach and contrast it with other airline pursuing alternative models. However, the fundamental problem is that is a lack of a consistent and standardised approach to analysing airline business models. This paper seeks to go someway towards rectifying this methodological gap.

\section{Product and organizational architecture}

Synthesizing complex airline business models requires the identification of key components of the product architecture - the service quality elements that define the product relative to consumer preferences, and organizational architecture - the vertical structure, production and distribution choices of the airline. A conceptual framework can be developed to consider both the product and organisational architecture of firms. Such a product and organizational architecture (POA) approach can be applied directly to airline business models. Figure 1 illustrates the general POA approach to defining a firm's business model and its competitive environment. On the one hand, product architecture gives rise to a core product bundle that positions the firm in terms of consumer preferences (benefit drivers) and the competitive environment (as defined by the market structure). On the other hand, the product design also implies a choice set for inputs and possible organizational structures (cost drivers) which define the firm's cost position. Taken 
together, both product and organizational architecture contribute to the creation and sustainability of profits.

\subsection{Applying the POA model to airlines}

Figure 2 shows an application of the POA approach to airline business models. By so doing we aim to develop a means by which airlines can be consistently compared. Product architecture is separated into three elements of service quality: connectivity, convenience and comfort. These three elements have the property that they follow a general ordering with respect to the degree with which costs are fixed or 'avoidable'. In particular, connectivity implies a choice of network design that distinguishes hub-and-spoke (airline-supplied connectivity) from point-to-point (passenger-supplied) networks. This is perhaps the most important core element that can distinguish between different airline business models.

Some of the elements of convenience are linked to network structure decisions, but nevertheless imply a lesser degree of fixed investment for some airlines. In particular, use of primary airports and 'checked-through' baggage services tend to follow from the choice of a hub-and-spoke network, however an airline operating a point-point network may also choose to offer convenience through use of a primary airport.

Elements of comfort in determining the quality of service are to some degree more variable than the other two categories, yet these elements will vary in importance for the overall architecture of the product. In some markets elements of comfort might be regarded as 'frills' while in other markets the same elements could be regarded as more essential; the offering of in-flight meals on short haul versus long-haul flights for example. The 3 Cs thus define the product in relation to 
consumer preferences, which impacts market demand within the competitive environment. However the 3Cs also impact the magnitude and avoidability of production costs which in turn affects pricing flexibility and the airline's competitive position.

\subsubsection{Organizational architecture}

Within the organizational architecture the size and composition of the fleet along with the organizational design are elements that follow on primarily from the product architecture. In particular, the decision over network structure is key because the complexity of operating a hub-and-spoke network requires certain functions relating to coordination, yield management, etc. which implies a more vertically integrated organization. In contrast, an airline operating a point-to-point network has relatively more opportunities to form a 'nexus of contracts' organizational structure in which many functions are contracted out.

In terms of distribution, all airlines now take advantage of internet based booking systems, yet even here point-to-point network carriers can offer more simplicity in the process with implications for both cost and benefit drivers

FIGURE 1 ABOUT HERE

FIGURE 2 ABOUT HERE

\subsubsection{Using indices to form benchmark metrics in the POA model}

In an attempt to functionalise the conceptual POA model, a dataset of benchmark metrics has been developed. By developing separate indices for different elements in the business model the interaction between the items and the importance of 
each item to the overall performance of each airline can be more easily identified and their impact on the overall performance assessed.

The indices were developed for each of the following areas:

- Profitability

- Cost drivers

- Revenue achievement

- Connectivity

- Convenience

- Comfort

- Distribution/Sales

- Aircraft productivity

- Labour productivity

- Airports Attractiveness

- Market Structure

The profitability index was constructed using just the operating ratio of the carriers in the benchmark group.

While profitability identifies the overall success of the business, an airline's unit cost (operating cost per ASK) summaries that various organizational architecture decisions made. It summarises the key cost values for the airline. The cost driver index is therefore a summary of the carriers' strategies with respect of IT, distribution and sales, aircraft, labour, and the airports served. Each of these items (with the exception of $\mathrm{IT}^{1}$ ) are treated with a separate index as detailed below.

The Revenue Index is a measure of the revenue side of the carriers' businesses and incorporates a number of revenue benchmarks. The prime measure is yield per RPK. Also included is operating revenue per sector (GBP). This will highlight differences between the large aircraft/high density aircraft and the smaller aircraft/higher yield operators. The final benchmark item included here is a simple

\footnotetext{
${ }^{1}$ The IT infrastructure within an airline can have significant influence over that business' costs. Unfortuanately, IT costs are not routinely reported in airline annual reports and therefore a separate IT index has not been possible to construct.
} 
measure of average fare paid per passenger (this incorporates ancillary revenues where these are reported separately).

While some airlines have quite a dense network from their main base, the coverage of their network elsewhere may be quite limited and therefore the number of departure per airport per day indicates the coverage of the network. The connectivity index, therefore, seeks to calculate an index of network density. It is calculated from four benchmark statistics: the number of departures per airport per day; the average frequencies per route per week; the number of routes offered and the total number of destinations available at the airport. For some airlines in a growth phase a strategy of serving a large number of small markets is pursued (e.g. Ryanair), while some other low cost carriers seek to usurp the short haul networks of traditional full service carriers (e.g. EasyJet).

Some airlines position themselves as providing a more convenient service by having a higher frequency of service, using airports either better located or with better surface transport links than those offered to alternative airports. They also promote a punctual service, and offer improved baggage services. For the Convenience Index the following benchmarks were included; the average weekly frequency per route ${ }^{2}$, the weighted average distance of the airport served to the city centre; the proportion of flights offered from primary airports, the proportion of flights departed on within 15 minutes, and the Skytrax ${ }^{3}$ baggage score.

To measure on-board comfort the seat pitch and seat width was included in the Comfort Index. The average number of passengers per flight was also included with fewer passengers per flight assumed to be more comfortable than more ${ }^{4}$. The

\footnotetext{
${ }^{2}$ While this benchmark statistic is also included in the connectivity index it is also a clear measure of convenience.

${ }^{3}$ Skytrax ratings for baggage handling for General handling, on-board baggage policy, excess baggage policy were aggregated and used for this rating.

${ }^{4}$ Although it is recognised that, depending on the type of aircraft equipment, smaller aircraft are not necessarily more comfortable for passengers than larger aircraft.
} 
final variable included in index is the number of passengers per flight-and-cabincrew member.

Changes to the distribution strategy of many carriers have been remarkable since low cost airlines began using the internet as their principal distribution channel in a bid to reduce their costs in this area. Two variables are included in the

Distribution/Sales Index; the percentage of sales made via the airline's online reservation system; and the airline's cost per passenger of ticketing, sales and promotion (TSP).

The Aircraft Productivity Index looks at both the daily utilisation of an airline's fleet and also the number of sectors each aircraft operates a day. While average sector length will affect each airline's ability to improve utilisation it is not included in this index as it can be used later to assess sector length impacts on the various performance indices. The uniformity of the fleet has often been highlighted as one of the key cost saving items for low cost airlines. A third variable in this index is then the percentage that the most populous aircraft type/mark accounts for in the fleet - this importance of fleet uniformity may therefore be assessed.

The Labour Productivity Index has four items contributing the aggregate index value. The index summarises the airline's employees productivity in relation to the number of passengers uplifted, and ASKs, the cost of personnel (per ASK). One area where carriers have recently been able to reduce costs is in the reduction of non-flying employees (e.g. in 2003 and 2004 British Airways reduced employee numbers significantly with the vast majority of loses coming from staff employed in non-flying roles). Therefore a higher proportion of flying employees is likely to increase employee productivity and this ratio is also included in this index. To recognize and try to reflect the effect of outsourcing that might otherwise inflate 
the employees productivity ratings, the passengers per employee ratio has been deflated by the percentage of total costs are accounted for by employee costs. This proportion may be considered a proxy measure for amount of outsourcing that a company does. If the proportion of employee costs over total costs is small then it is more likely that the airline outsourced operational activities, whereas an airline with a higher proportion of employee costs over total costs are likely to have undertaken more operational activities in-house. The authors recognize the potential flaws using this ratio to adjust the benchmark labour productivity variable (i.e. one airline pays considerably lower wages), however outsourcing is a significant part of the low cost model and the degree to which an airline outsources is very difficult to measure from published sources. Therefore this proxy for outsourcing is used to deflate labour productivity measures.

One of the key sources of lower costs that some low cost carriers have been able to achieve has been in airport charges. The Airport Attractiveness Index attempts to rate the airlines' success at managing this cost item. Four benchmark variables are included. Firstly the airport/en-route cost per passenger is calculated. Secondly, smaller airports are likely to offer lower landing fees and thus a variable is included for the weighted average annual passengers at the airport. Where an LCC operates to an airport with higher number of full service carriers present the opportunity to negotiate lower fares is reduced, and thus the third variable included is the weighted average number of full service carriers at the airports served. Finally the percent of city pair routes that are monopolies provides a measure of how important the airline is to the airport and thus a measure of negotiating power.

The final index provides a measure of the market structures that each airline operates within. The median and average HHI scores are calculated across each airline's network. This Market Structure Index also incorporates the average 
number of competitors per route each airline faces, the average city size served and the average share of capacity (by seats) per route.

\subsubsection{Index calculation methodology}

To demonstrate the use of the POA model to consistently compare airline business models it was applied to the European LCC sector using six sample airlines. The airlines considered were; EasyJet, Ryanair, Norwegian, Flybe, SkyEurope and Air Berlin for both fiscal years 2005 and 2006. Where possible the items in the conceptual model were included in the analysis. As the benchmarks are calculated using published data sources (generally the annual reports of the various airlines in question and Air Transport Intelligence ${ }^{5}$ ), not every item in the conceptual model could be mapped directly by the benchmarks. However, every attempt has been made to construct a benchmark dataset that as closely reflects the items in the conceptual model.

The airlines in the sample represent a range of business models and inclusion of a two year's of data for each airline means that changes in business model or performance can be identified. In an earlier draft of this work (presented at ATRS 2006) the authors presented an integrated index that aimed to describe the airline in a spectrum of low cost airline business models. However subsequent work has shown that the interaction between the various elements described above in the business model tend to be lost in the benchmarking process by aggregating items together. Consequently, here a number of separate indices have been developed.

The methodology adopted to calculate the eleven index scores per airline is based on "best in class" performance by the sample airlines for each item benchmarked. For most benchmarks the highest score represents the "best in class" - e.g. ASKs per employee - if each employee produces a large number of ASKs the

\footnotetext{
${ }^{5}$ www.rati.com
} 
performance of the airline's employee productivity is likely to be high. In some cases the "best in class" is the lowest score - e.g the airline that achieves the lowest unit costs per ASK in the benchmark pool is clearly the "best in class". In some cases the directional preference of the benchmark is not obvious and a value judgment is required. For example, when considering network density it is not clear whether the best airline is the one that has the highest or lowest network density. In this case the "best in class" is considered to be the airline with the highest benchmark statistic and the aggregate index is used to see further examine the impact of the network decisions on the performance of the airline.

The benchmark values for the sample airlines in 2006 are detailed in the table below. The variables included in each index are shown.

\section{TABLE 1 ABOUT HERE}

Of the airlines in the benchmark panel Ryanair and easyJet were both profitable in both selected years. Newly established Sky Europe is some way off profitability. Recently established Norwegian and FlyBe (which changed its operation from regional services to low cost carrier services in 2002), are profitable in one of the two years. Air Berlin that is the third largest carrier of the group behind Ryanair and EasyJet has moved into a profitable position in 2006 after beginning to refocus its operations in the low cost sector over the past couple of years. Ex-regional carrier, FlyBe is the only one of the carriers that operates a number of different aircraft and does not have either B737 or A320 type aircraft in its fleet.

\section{Calculation of Maximum "Best in Class" Index}

The following calculation procedures were applied to calculate each Index. For items that for which the highest score was considered "Best in Class" the following the highest score was identified. For each airline (and for each year) a ratio was calculated for dividing the airline's performance by the "best in class" value. 
Benchmark Ratio $=$ Airline's performance/Best in class performance

Here the top mark available will be 1.0 and this will be achieved by the "best in class" performer. The other airlines in the sample will be allocated a mark that represents their performance as a percentage of the best in class. For example, the following calculation was performed to establish EasyJet's 2006 performance ratio in the Profitability/Operating benchamark area.

- Best in class $=132.4 \%$ Op profit (achieved in this case by Ryanair in 2005)

- EasyJet, $2005=108.7 \%$ Op profit

Therefore

EasyJet 2006 Op Profit Benchmark Ratio $=105.1 / 132.4=\mathbf{0 . 7 9}$

In other words easyJet's operating profit performance is $79 \%$ that of Ryanair's.

\section{Calculation of Minimum "Best in Class" Index}

For calculating a benchmark ratio for items where a minimum value was considered the "best of class" the ratio was constructed to place the performance of the individual airline on a continuum from "best in class" to "worst in class" Class)

Benchmark Ratio $=($ Worst in Class - Airline Performance $) /($ Worst in Class - Best in

For example, again looking at easyJet's performance in 2005 , this time considering unit cost

- $\quad$ Best in Class $=2.30$ pence per ASK (achieved by Ryanair in 2006)

- Worst in Class $=8.48$ pence per ASK (Flybe, 2005)

- EasyJet, $2005=3.97$ pence per ASK

EasyJet Unit Cost Benchmark Ratio $=(8.48-3.97) /(8.48-2.30)=0.73$

Here the worst performer in the benchmark group will achieve a zero benchmark ratio. The advantage of this approach is that it draws all airlines within the benchmark sample group across a range from zero (the worst) to one (the best). 
Due to the requirement to include a "worst in class" value in the calculation to establish the range of values the ratio indicates where in that spectrum of performance each airline is. In this case easyJet's performance is $73 \%$ along the spectrum for worst to best.

\subsubsection{Application of Weighting}

In the calculation of each index it was felt appropriate that some items in each index made a greater contribution to the final index and therefore a weighting process was applied. The weights were based on a correlation of the benchmark item against profitability. The range of weight values can be from zero to one with one carrying the greatest weight. For each index a calculation is made to apply the weight to each benchmark ratio item and then a total is summed.

Weighted score $=\left(\left(\right.\right.$ score $_{a} *$ weight $\left._{i}\right)+\left(\right.$ score $_{b} *$ weight $\left._{i i}\right)+\ldots+\left(\right.$ score $_{z} *$ weight $\left.\left._{n}\right)\right) /$ Lweights $_{i-n}$

\section{TABLE 2 ABOUT HERE}

\subsubsection{Calculation of Final Index}

This final indexing places all airlines in relationship with the best performer in the area of analysis (such as Cost, Profitability, or Revenue, etc.). The score is calculated by establishing a ratio of the weighted score for each airline over the highest/best weighted score.

Final Index $=$ Weighted Score/Best Weighted Score*10

The results of the index calculations for the sampled airlines in the table below.

TABLE 3 ABOUT HERE

\subsection{Analysis of Indices}


By calculating separate indices for different areas of the business model, it is possible to develop a correlation matrix (Table 4).

\section{TABLE 4 ABOUT HERE}

The matrix reveals some interesting relationships. While cost is, as expected for low cost carriers, correlated with profitability (with a correlation coefficient of 0.27 ), the poor profitability of SkyEurope (which ironically has very low costs) has drawn down the correlation from 0.54 if they had been excluded from the benchmark group. The labour index is highly correlated with profitability (0.86). As for most airlines, labour is the single largest controllable cost it is not surprising that those airlines that are best at getting high productivity from their labour will be more likely to be profitable. Indeed there is a very high correlation between the cost and labour indicies indicating that low cost airlines that achieve high labour productivity are a long way toward ensuring low costs. Aircraft productivity is also highly correlated to profitability indicating that a successful low cost carrier will work its aircraft assets very hard. Two indicies that are reasonably well correlated to profitability is connectivity and airports (with correlation coefficients of 0.47 and 0.59 respectively). The airlines in the benchmark group that have the best profitability tend also to have larger networks, offer more routes or have higher density networks. The airline with the best profitability (Ryanair) also has a large proportion of monopoly routes in small, secondary networks and face limited competition from full service carriers.

Two key indicies that are inversely correlated to profitability for this panel of benchmark low cost carriers are convenience and comfort, whilst being correlated with the revenue index. This would suggest that in the low cost sector providing additional levels of comfort to customers and chasing higher yielding passengers 
does not attain the best financial rewards. The high inverse correlation between the revenue and cost indicies seem to suggest that the pursuit of higher yields and lower cost are mutually exclusive. In this airline sector carriers need to focus on costs and productivity rather than moving into a middle ground where higher levels of comfort and higher yields are provided and sought.

\subsection{Key findings on the low cost carrier sector revealed by application of the POA model}

The original concept for this research was to highlight the point that airlines that called themselves "low cost" did not necessarily have the lowest costs, and that within the sector a number of different business models were being practiced. The concept was extended to highlight differences in business models. In an earlier working paper (Morrison and Mason, 2007) we concluded that more than one LCC model might be possible but more work was required on the indexes and the benchmark data that supports them. From here the POA concept was formulated to test this hypothesis. The two figures that follow lay out the index profiles of the six benchmark airlines in 2006 . The further a carrier is toward the outermost point on a spoke the closer they are to being the best in class for that particular index. A score of 10 for a particular index means the airline is the best in class. We can see that Ryanair has a profile that is best in six of the eleven indexes (and as such it is also included in the second chart for reference). They are best in class for profitability, cost, distribution, labour, airport attractiveness, and market structure. They are second best for aircraft productivity. It would seem therefore that, in this benchmarking exercise, Ryanair is best in delivering an organizational architecture that attains the best profitability. Part of that success leads to, and derives from, a market structure where they dominate the small markets that they serve. It is in the product architecture area where Ryanair is not the best in class. In fact, it is worst in class for Revenue, Comfort and Convenience. It would seem that the 
carriers that pursue revenues backed by additional comfort and convenience are those that have failed to achieve good profitability suggesting that such a model that is less successful in the low cost sector.

\section{FIGURE 3 ABOUT HERE}

FIGURE 4 ABOUT HERE

Connectivity remains the index that does not have a clear outcome. Ryanair scores more highly than Flybe, Norwegian and SkyEurope on account of its significantly higher number of routes. EasyJet has the best connectivity index scores due to its higher network density, higher frequencies, and tendency to serve larger airports that have more available destinations. However, easyJet's network density has fallen consistently since 2003 when it had 12 departures per airport per day and an average weekly flight frequency of 32.6 per route. In 2006 the airline had reduced its number of departures per airport per day to 9.4 and reduced its weekly average frequency per route to 18.6 - still the highest in the benchmark panel but a significant change in strategy. As new European countries entered the EU, both Ryanair and EasyJet have been looking to extend their network and increase the number of routes offered. Ryanair, with its already low density strategy, has done so without further thinning its network density, however, easyJet's new strategy of network expansion has been at the cost of its route density and flight frequency. During this period of new opportunities, first mover advantage would seem to have been important. However, it is still not clear at this time whether network connectivity is vital to the success of a LCC and it will be a couple of more year's before this becomes clear.

\section{FIGURE 5 ABOUT HERE}


Figure 6 provides a clear illustration of the cost implications of product design by relating the cost and comfort indexes of the airlines. The figure shows that Ryanair display low levels of comfort but enjoying the best cost index in the benchmark panel. In contrast Sky Europe with high crew to passenger ratios and lower average passengers per flight and FlyBe with the advantage of smaller aircraft have the best comfort index values but low cost index scores.

\section{FIGURE 6 ABOUT HERE}

Regarding sector length, most of the carriers in the benchmark panel have average stage lengths of between 800 and 1,100 km. With the inclusion of newly purchased dba (formerly BA owned Deutsche BA) in its figures, Air Berlin has significantly changed it operating pattern in 2006 and joins all other benchmark airlines with the exception of FlyBe in the central range of average sector lengths. As a previously regional carrier offering very short sectors FlyBe offer a different model to those offered by the rest of the benchmark group. It's marginal profitability suggests that it model is not particularly successful however its performance is no worse than Norwegian or Air Berlin that follow the normal low cost model more closely.

\section{FIGURE 7 ABOUT HERE}

While there most carriers in the benchmark group have similar average stage lengths, one important part of the low cost model is the effective use of aircraft assets. The two leading carriers, Ryanair and Easyjet both get more flights per day out of their aircraft assets than the other carriers in the panel. Additional flights per day mean more opportunities to share the cost of aircraft ownership and overhead cost over a larger number of passengers. Given the significantly shorter sector lengths it flies, Flybe may be able to increase the number of sectors it operates per day and thereby, possibly, contribute to making its model a success. 
FIGURE 8 ABOUT HERE

\subsection{Conclusion}

Meaningful definitions of and distinctions between airline business models are not easily formulated, particularly when one considers the extremely dynamic nature of the industry. In order to provide a more coherent and consistent understanding of airline competition and strategy, we have applied a product and organizational architecture (POA) approach to classifying and relating key elements of airline business models.

The application of the POA model to six European airlines has shown that there are important differences in the business models of airlines who are all commonly referred to as 'low cost carriers'. Our paper demonstrates how differences in the business models adopted by the different airlines contribute to their profitability. More specifically, amongst the sample airlines examined, our analysis suggests that the positioning of some airlines to offer increased comfort and convenience in a bid to achieve higher yields is marginally successful but is not as profitable as the pure low cost approach practised by Ryanair.

There may well be a first mover advantage enjoyed by Ryanair and EasyJet. Certainly size and market power are shown to contribute to the POA strategy of both airlines. Yet, we can see that even between these two airlines, Ryanair stands alone as the lowest-cost carrier, providing some indication that strategically, when one airline establishes a lowest cost position in its product and organizational architecture, competitors are forced to choose a different POA strategy. Casual 
support for this is provided by recent marketing efforts by Easyjet, aimed at driving up the proportion of traffic that is business related. The direct objective of targeting this market is to drive up yield, but there is also strategic value adjusting their POA strategy thereby avoiding head-to-head direct competition with their lowest-cost competitor.

The analysis presented here can be extended in two ways. First by continuing to collect data covering a larger number of years, we can investigate how the POA of airlines in the sample have evolved over time. Secondly, the POA model can usefully be applied to analyse other airline models (subject to availability of data) full service carriers, premium only cabin carriers, long haul low cost carriers - and between carriers in similar sectors in different regions - low cost airlines in North America, Europe and Asia. 


\section{Acknowledgements}

We wish to acknowledge intellectual and financial support from the Centre for Transportation Studies at the University of British Columbia, Canada and particularly that of Prof David Gillen. Also, we thank GARS workshop participants in Hamburg, Germany and ATRS conference participants in Nagoya, Japan for useful comments on earlier drafts of this work.

\section{References}

Francis G., Alessandro F., and Humphreys I., 2003. Airport-airline interaction: the impact of low-cost carriers on two European airports, Journal of Air Transport Management, 9(4), pp 267-273.

Morrison W. and Mason K., 2007. Defining and comparing competitive business models in the context of product and organizational architecture, Working paper.

Williams, G. and Mason, K., 2004, Market analysis of Europe's low cost airlines: An examination of trends in the economics and operating characteristics of Euope's Charter and no-frills scheduled airlines. Air Transport Group Research Report 9. Air Transport Group, Cranfield University.

\section{Bibliography}

Dresner, M. and Windle, R., 1996. The Impact of Low-cost carriers on Airport and Route Competition, Journal of Transport Economics \& Policy, 30(3), pp 309-328.

Fernandez, M., and Kropac, M., 2004. Low-cost carrier: Hintergrunde und problematik des billigflugtrends im europaischen luftverkehr. Aussenwirtschaft, 59(4), 407-434.

Forsyth, P., 2003. Low-cost carriers in Australia: experiences and impacts, Journal of Air Transport Management, 9(5).

Gillen, G. and Lall, A., 2004. Competitive advantage of low-cost carriers: some implications for airports, Journal of Air Transport Management, 10(1).

Gillen D. and Morrison W., 2003. Bundling, Integration and the Delivered Price of Air Travel: Are Low-cost Carriers Full-service Competitors?, Journal of Air Transport Management, 9(1).

Mason, K.J., 2000. The Propensity for Business Travellers to use Short Haul, Low Cost Airlines, Journal of Transport Geography, Vol.8, No.2, pp. 107-119.

Willams G., 2001. Will Europe's charter carriers be replaced by "no frills" scheduled airlines?, Journal of Air Transport Management, 7(5), pp 277-286. 
Windle, R., \& Dresner, M., 1999. Competitive responses to low-cost carrier entry, Transportation Research: Part E: Logistics and Transportation Review, 35(1), pp 59 $-75$. 


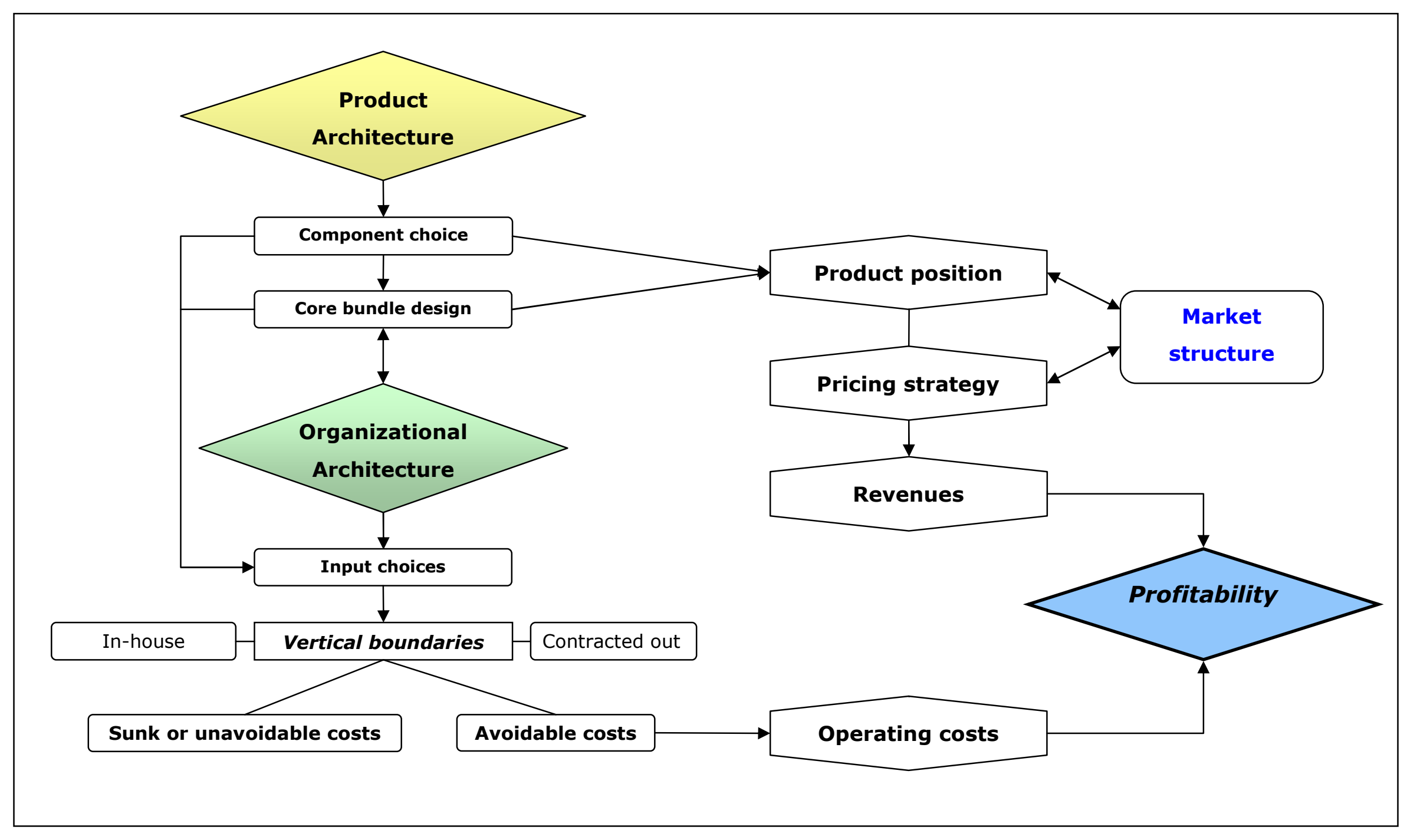

Figure 1

General product and organizational architecture of a firm 


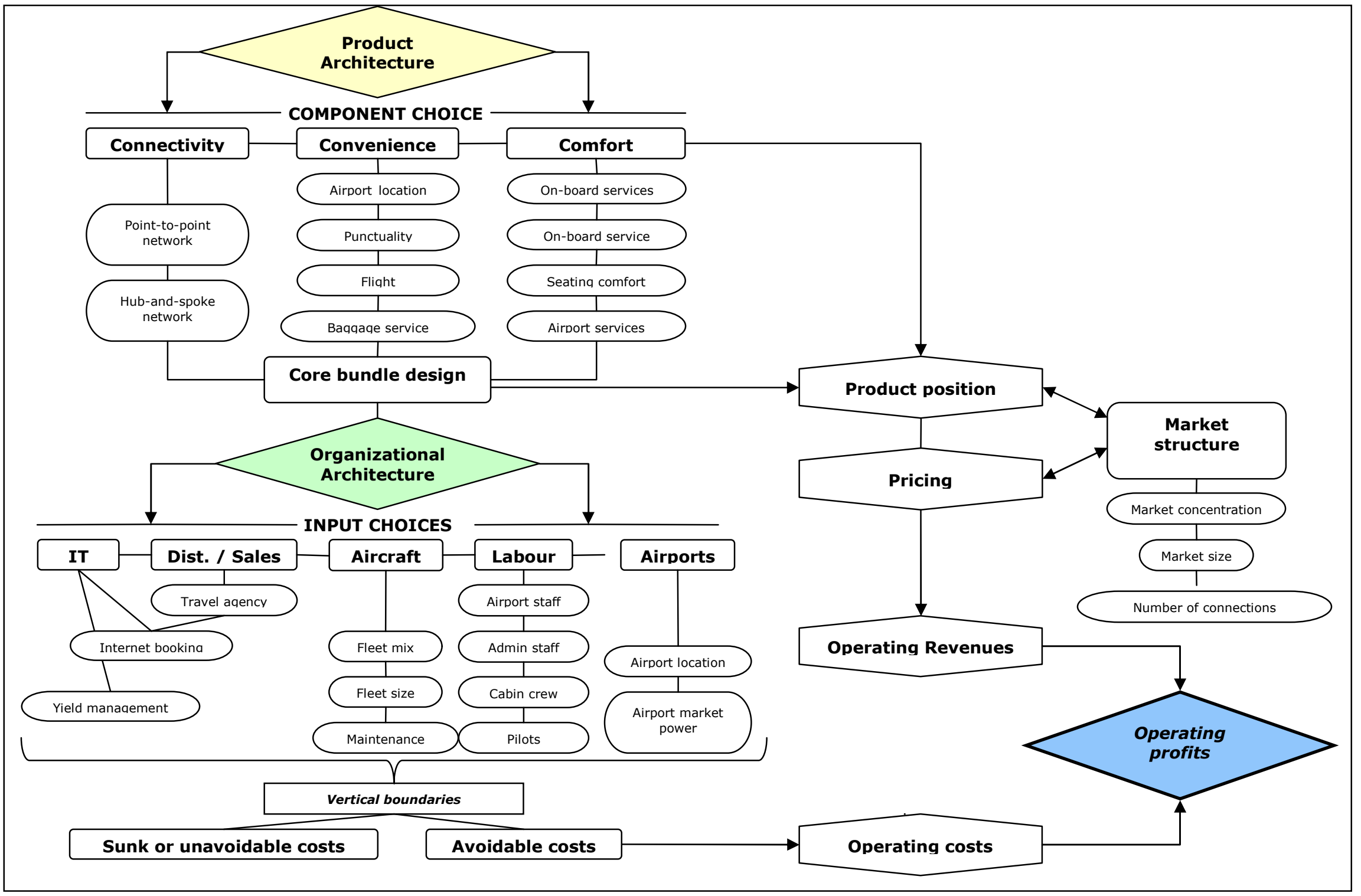

Figure 2

Schemata of Product and Organizational Architecture of Airlines 
Table 1: Benchmark data for selected 'low cost' airlines

\begin{tabular}{|c|c|c|c|c|c|c|}
\hline & $\begin{array}{c}\text { easyJet } \\
2006\end{array}$ & $\begin{array}{l}\text { Ryanair } \\
2006\end{array}$ & $\begin{array}{c}\text { Norwegian } \\
2006\end{array}$ & $\begin{array}{l}\text { FlyBe } \\
2006\end{array}$ & $\begin{array}{l}\text { SkyEurope } \\
2006\end{array}$ & $\begin{array}{c}\text { Air Berlin } \\
2006\end{array}$ \\
\hline Profitability/Op ratio & $108.7 \%$ & $128.5 \%$ & $99.0 \%$ & $99.9 \%$ & $74.1 \%$ & $102.2 \%$ \\
\hline Unit cost (per ASK) GBP pence & 4.02 & 2.30 & 4.68 & 7.17 & 3.95 & 3.35 \\
\hline \multicolumn{7}{|l|}{ Revenue Index } \\
\hline Yield per RPK (GBP pence) & 5.12 & 3.81 & 5.90 & 10.91 & 3.87 & 4.39 \\
\hline Operating revenue per sector (GBP) & 6,388 & 5,081 & 6,861 & 3,454 & 4,242 & 6,293 \\
\hline Average fare paid (GBP) (incl ancillary rev) & 49.08 & 33.22 & 48.77 & 60.73 & 42.31 & 54.50 \\
\hline \multicolumn{7}{|l|}{ Connnectivity Index } \\
\hline Network density - Departures per airport p.d. & 9.39 & 5.61 & 1.91 & 5.04 & 1.63 & 4.82 \\
\hline Routes offered & 176 & 284 & 56 & 95 & 53 & 273 \\
\hline All destinations available at airports served & 31.9 & 19.5 & 28.3 & 14.9 & 28.4 & 47.8 \\
\hline \multicolumn{7}{|l|}{ Convenience Index } \\
\hline Average frequency per route & 18.61 & 10.66 & 8.21 & 10.98 & 6.22 & 12.65 \\
\hline Airport location - ave dist nearest pop'n centre $(\mathrm{km})$ & 23.7 & 25.2 & 30.3 & 9.6 & 13.5 & 12.8 \\
\hline Flights at primary airports & $36 \%$ & $27 \%$ & $42 \%$ & $33 \%$ & $41 \%$ & $57 \%$ \\
\hline Punctuality & $66 \%$ & $70 \%$ & $71 \%$ & $77 \%$ & $69 \%$ & $63 \%$ \\
\hline Baggage Service (Skytrax rating) & 1.67 & 1 & 2.67 & 2.33 & 1.67 & 2.67 \\
\hline \multicolumn{7}{|l|}{ Comfort Index } \\
\hline Passengers per flight & 130.2 & 153.0 & 140.7 & 56.9 & 100.3 & 115.5 \\
\hline Passengers per flight and cabin crew members & 8980 & 14542 & 9668 & 7036 & 6775 & 9172 \\
\hline Economy Seat width & 17.5 & 17.2 & 17.2 & 17 & 17.5 & 17.2 \\
\hline Economy seat pitch & 29 & 30 & 30 & 31 & 29 & 0 \\
\hline \multicolumn{7}{|l|}{ Distribiution/Sales Index } \\
\hline Ticketing, Sales, Promotion per pax (GBP) & 1.70 & 0.27 & 1.54 & 3.78 & 2.75 & 2.09 \\
\hline Internet distribution (\%) & $98 \%$ & $98 \%$ & $84 \%$ & $85 \%$ & $56 \%$ & $45 \%$ \\
\hline \multicolumn{7}{|l|}{ Aircraft Index } \\
\hline Aircraft Utlilisation (aircraft hours per day) & 11.6 & 9.6 & 10.4 & 5 & 9.29 & 11.5 \\
\hline Most populous aircraft type/mark accounts for fleet & $71.3 \%$ & $100.0 \%$ & $100.0 \%$ & $74.4 \%$ & $100.0 \%$ & $63.6 \%$ \\
\hline Aircraft sectors per day & 6.03 & 6.56 & 5.23 & 5.53 & 5.00 & 5.59 \\
\hline \multicolumn{7}{|l|}{ Labour Index } \\
\hline Pax per employee & 7,571 & 11,270 & 6,349 & 2,858 & 2,957 & 5,972 \\
\hline Employees per aircraft & 39.8 & 33.5 & 42.3 & 40.2 & 61.9 & 46.7 \\
\hline Personnel cost per ASK & 0.49 & 0.30 & 0.65 & 0.99 & 0.38 & 0.35 \\
\hline Flight and cabin crew/total employees & $84.3 \%$ & $77.5 \%$ & $65.7 \%$ & $40.6 \%$ & $43.6 \%$ & $65.1 \%$ \\
\hline ASK per employee ('000) & 8,508 & 12,667 & 6,680 & 2,423 & 4,276 & 9,518 \\
\hline \multicolumn{7}{|l|}{ Airport Index } \\
\hline Percent of city pair routes are monopolies & $39.8 \%$ & $64.4 \%$ & $51.8 \%$ & $72.6 \%$ & $69.8 \%$ & $42.8 \%$ \\
\hline Weighted ave Annual pax at airports served (m) & 5.25 & 2.67 & 4.63 & 1.95 & 4.11 & 7.12 \\
\hline No of network airlines at destination & 4.6 & 1.6 & 5.5 & 2.1 & 5.0 & 7.3 \\
\hline airport/enroute costs per pax (£) & 11.50 & 7.47 & 12.46 & 24.08 & 15.60 & 18.51 \\
\hline \multicolumn{7}{|l|}{ Market Structure Index } \\
\hline Median HHI on Capacity (seat) & 6195 & 10000 & 10000 & 10000 & 10000 & 5600 \\
\hline Average HHI on Capacity (seat) & 6736 & 8038 & 7631 & 8679 & 8216 & 6758 \\
\hline Average no of competitors per route & 2.31 & 1.67 & 1.77 & 1.38 & 1.66 & 2.14 \\
\hline Capacity share of seats & $64.0 \%$ & $80.5 \%$ & $70.9 \%$ & $84.7 \%$ & $78.8 \%$ & $64.2 \%$ \\
\hline Average city size served & 677522 & 451020 & 307038 & 192007 & 438881 & 665902 \\
\hline
\end{tabular}


Table 2: Weighting of benchmark metrics to operating profit Index items

Correlations/weights

\section{Cost drivers weighting}

Unit cost (per ASK) GBP pence $\quad-0.35$

Revenue Weighting

Yield per RPK (GBP pence)

$-0.12$

Operating revenue per sector (GBP)

0.14

Average fare paid (GBP) (incl ancillary rev)

Connectivity Weighting

Network density - Departures per airport p.d.

Routes offered

Average Flight Frequency

$-0.01$

All destinations available at airports served $\quad-0.57$

\section{Convenience Weighting}

Average frequency per route

Airport location - ave distance from nearest $\quad 0.50$

population centre $(\mathrm{km})$

Flights at primary airports $\quad-0.47$

Punctuality $\quad 0.24$

Baggage Service (Skytrax rating) $\quad-0.40$

\section{Comfort Weighting}

Passengers per flight $\quad 0.56$

Passengers per flight and cabin crew members $\quad 0.87$

Economy Seat width $\quad 0.17$

Economy seat pitch $\quad 0.24$

Distribution/Sales weighting

Ticketing, Sales, Promotion per pax (GBP) $\quad-0.34$

Internet distribution (\%) $\quad 0.58$

Aircraft productivity weighting

Aircraft Utlilisation (aircraft hours per day) 0.13

Most populous aircraft type/mark accounts for $\quad-0.27$

fleet

Aircraft sectors per day

Labour productivity weighting

Pax per employee

Pax per employee adjusted by $\%$ emp cost/tot

cost

Employees per aircraft $\quad-0.74$

Personnel cost per ASK $\quad-0.26$

Flight and cabin crew/total employees $\quad 0.46$

ASK per employee ('000) $\quad 0.60$

Airports Weighting

Percent of city pair routes are monopolies $\quad-0.21$

Weighted ave Annual pax at airports served $(\mathrm{m}) \quad-0.20$

No of full service airlines at destination $\quad-0.51$

airport/enroute costs per pax $(£) \quad-0.60$

Market Structure weighting

Median HHI on Capacity (seat) $\quad-0.05$

Average $\mathrm{HHI}$ on Capacity (seat) $\quad-0.18$

Average no of competitors per route $\quad 0.12$

Capacity share of seats $\quad-0.02$

$\begin{array}{ll}\text { Average city size served } & 0.17\end{array}$ 
Table 3: POA Index scores for benchmark airlines (2005, 2006)

\begin{tabular}{|c|c|c|c|c|c|c|c|c|c|c|c|c|}
\hline SUMMARY & $\begin{array}{l}\text { easyJet } \\
2005\end{array}$ & $\begin{array}{c}\text { easyJet } \\
2006\end{array}$ & $\begin{array}{c}\text { Ryanair } \\
2005\end{array}$ & $\begin{array}{c}\text { Ryanair } \\
2006\end{array}$ & $\begin{array}{c}\text { Norwegian } \\
2005\end{array}$ & $\begin{array}{c}\text { Norwegian } \\
2006\end{array}$ & FlyBe 2005 & FlyBe 2006 & $\begin{array}{c}\text { SkyEurope } \\
2005\end{array}$ & $\begin{array}{c}\text { SkyEurope } \\
2006\end{array}$ & $\begin{array}{l}\text { Air Berlin } \\
2005\end{array}$ & $\begin{array}{c}\text { Air Berlin } \\
2006\end{array}$ \\
\hline Profitability Index Score & 7.48 & 8.07 & 10.00 & 9.76 & 6.49 & 6.22 & 5.70 & 5.22 & 1.42 & 0.92 & 6.55 & 6.70 \\
\hline Cost driver Index score & 7.30 & 7.22 & 9.84 & 10.00 & 5.98 & 6.15 & 0.00 & 2.13 & 7.38 & 7.33 & 8.54 & 8.31 \\
\hline Revenue Index & 7.27 & 7.86 & 5.48 & 5.52 & 8.40 & 8.01 & 10.00 & 9.34 & 6.61 & 6.45 & 9.65 & 8.42 \\
\hline Connectivity Index & 7.38 & $\begin{array}{l}8.00 \\
8.09\end{array}$ & $\begin{array}{l}7.40^{\circ} \\
6.23\end{array}$ & 7.86 & $\begin{array}{l}0.40 \\
3.35\end{array}$ & 3.93 & 4.02 & $\begin{array}{l}.54 \\
4.16\end{array}$ & $\begin{array}{l}3.01 \\
3.08\end{array}$ & $\begin{array}{l}0.45 \\
3.81\end{array}$ & $\begin{array}{l}.030 \\
8.70\end{array}$ & $\begin{array}{l}0.42 \\
10.00\end{array}$ \\
\hline Convenience Index & 6.05 & 6.20 & 4.34 & 4.83 & 6.46 & 6.62 & 9.06 & 9.12 & 8.08 & 8.12 & 9.95 & 10.00 \\
\hline Comfort Index & 5.95 & 6.12 & 2.54 & 2.46 & 5.50 & 5.42 & 10.00 & 9.69 & 9.92 & 8.29 & 5.39 & 5.20 \\
\hline Distribution/Sales index & 9.05 & 9.00 & 9.85 & 10.00 & 7.36 & 8.22 & 5.13 & 6.72 & 5.26 & 5.58 & 4.01 & 5.33 \\
\hline Aircraft Index & 8.64 & 8.96 & 9.61 & 10.00 & 8.02 & 8.80 & 8.31 & 7.85 & 8.03 & 8.45 & 8.21 & 8.33 \\
\hline Labour Index & 7.45 & 7.40 & 9.71 & 10.00 & 6.20 & 6.29 & 3.02 & 3.78 & 2.94 & 2.92 & 6.19 & 6.09 \\
\hline Airports Attractiveness Index & 6.54 & 5.85 & 10.00 & 9.73 & 5.98 & 5.53 & 5.60 & 5.70 & 5.92 & 5.54 & 2.77 & 2.20 \\
\hline Market Structure Index & 8.16 & 8.19 & 9.42 & 9.98 & 7.91 & 8.57 & 9.09 & 9.67 & 9.34 & 10.00 & 7.97 & 8.59 \\
\hline
\end{tabular}


Table 4: Correlation Matrix of POA Indicies

\begin{tabular}{|c|c|c|c|c|c|c|c|c|c|c|c|}
\hline Correlation Matrix & $\begin{array}{l}\text { Operating } \\
\text { Ratio }\end{array}$ & $\begin{array}{c}\text { Cost } \\
\text { driver } \\
\text { Index }\end{array}$ & $\begin{array}{c}\text { Revenue } \\
\text { Index }\end{array}$ & $\begin{array}{l}\text { Connectivity } \\
\text { Index }\end{array}$ & $\begin{array}{c}\text { Convenience } \\
\text { Index }\end{array}$ & $\begin{array}{l}\text { Comfort } \\
\text { Index }\end{array}$ & $\begin{array}{l}\text { Distribution/ } \\
\text { Sales index }\end{array}$ & $\begin{array}{l}\text { Aircraft } \\
\text { Index }\end{array}$ & $\begin{array}{l}\text { Labour } \\
\text { Index }\end{array}$ & $\begin{array}{l}\text { Airports } \\
\text { Index }\end{array}$ & $\begin{array}{c}\text { Market } \\
\text { Structure } \\
\text { Index }\end{array}$ \\
\hline Operating Ratio & 1.00 & 0.27 & -0.25 & 0.47 & -0.60 & -0.75 & 0.70 & 0.75 & 0.86 & 0.59 & -0.01 \\
\hline Cost driver Index score & 0.27 & 1.00 & -0.71 & 0.53 & -0.44 & -0.76 & 0.36 & 0.57 & 0.66 & 0.23 & -0.03 \\
\hline Revenue Index & -0.25 & -0.71 & 1.00 & -0.02 & 0.74 & 0.48 & -0.61 & -0.70 & -0.49 & -0.72 & -0.49 \\
\hline Connectivity Index & 0.47 & 0.53 & -0.02 & 1.00 & 0.03 & -0.58 & 0.14 & 0.38 & 0.59 & -0.20 & -0.31 \\
\hline Convenience Index & -0.60 & -0.44 & 0.74 & 0.03 & 1.00 & 0.62 & -0.93 & -0.78 & -0.73 & -0.88 & -0.11 \\
\hline Comfort Index & -0.75 & -0.76 & 0.48 & -0.58 & 0.62 & 1.00 & -0.63 & -0.76 & -0.94 & -0.40 & 0.16 \\
\hline Distribution/Sales index & 0.70 & 0.36 & -0.61 & 0.14 & -0.93 & -0.63 & 1.00 & 0.77 & 0.78 & 0.79 & 0.08 \\
\hline Aircraft Index & 0.75 & 0.57 & -0.70 & 0.38 & -0.78 & -0.76 & 0.77 & 1.00 & 0.82 & 0.73 & 0.30 \\
\hline Labour Index & 0.86 & 0.66 & -0.49 & 0.59 & -0.73 & -0.94 & 0.78 & 0.82 & 1.00 & 0.54 & -0.16 \\
\hline Airports Index & 0.59 & 0.23 & -0.72 & -0.20 & -0.88 & -0.40 & 0.79 & 0.73 & 0.54 & 1.00 & 0.49 \\
\hline Market Structure Index & -0.01 & -0.03 & -0.49 & -0.31 & -0.11 & 0.16 & 0.08 & 0.30 & -0.16 & 0.49 & 1.00 \\
\hline
\end{tabular}


Figure 3: Spider web Profile, Ryanair, EasyJet and Air Berlin (2006)

LCC Profile, 2006

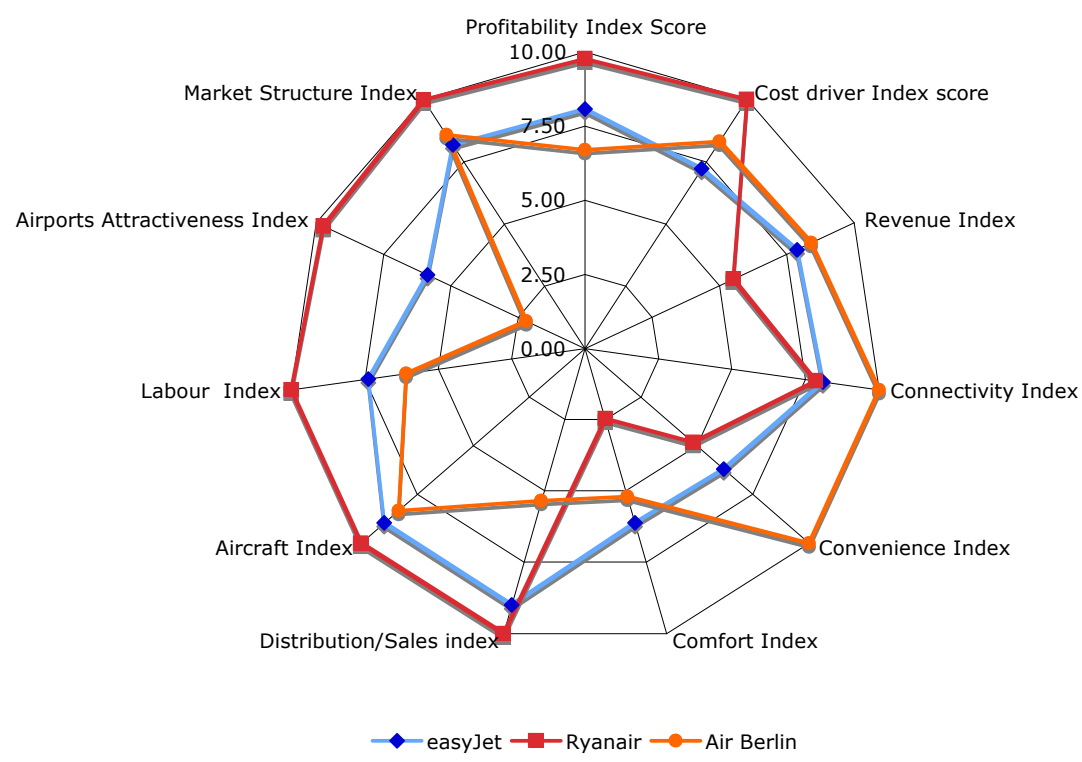


Figure 4: Spider web Profile: FlyBe, SkyEurope, Norwegian (2006) LCC Profile, 2006

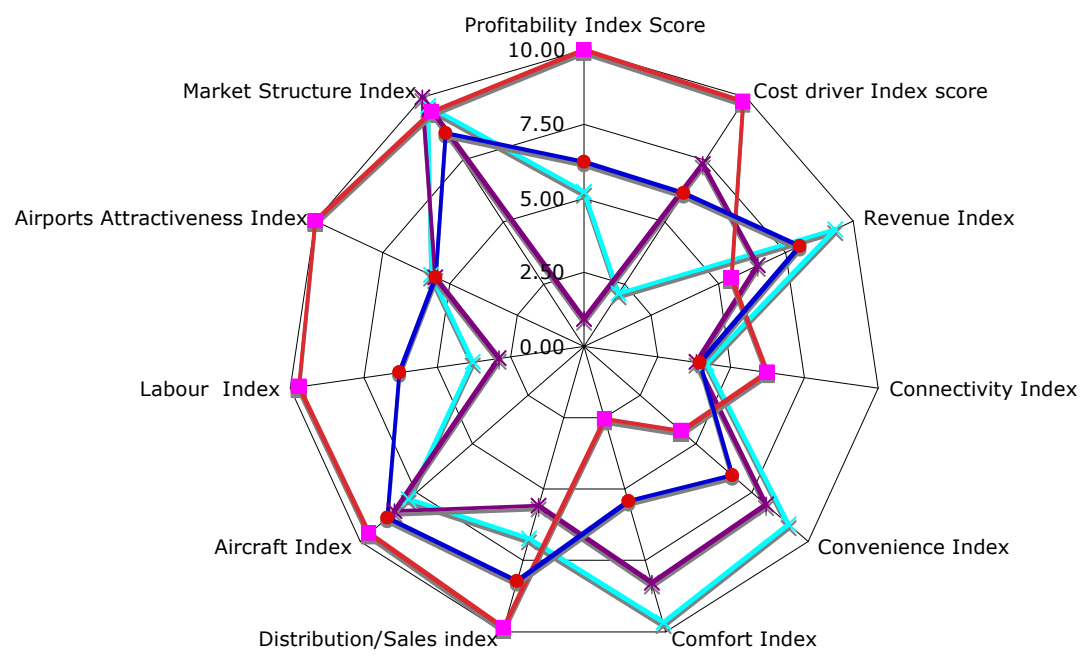

$\leftarrow$ FlyBe $\rightarrow$ SkyEurope - -Ryanair $\longrightarrow-$ Norwegian 
Figure 5: Operating Ratio and Connectivity Index

Operating Ratio and Connectivity Index

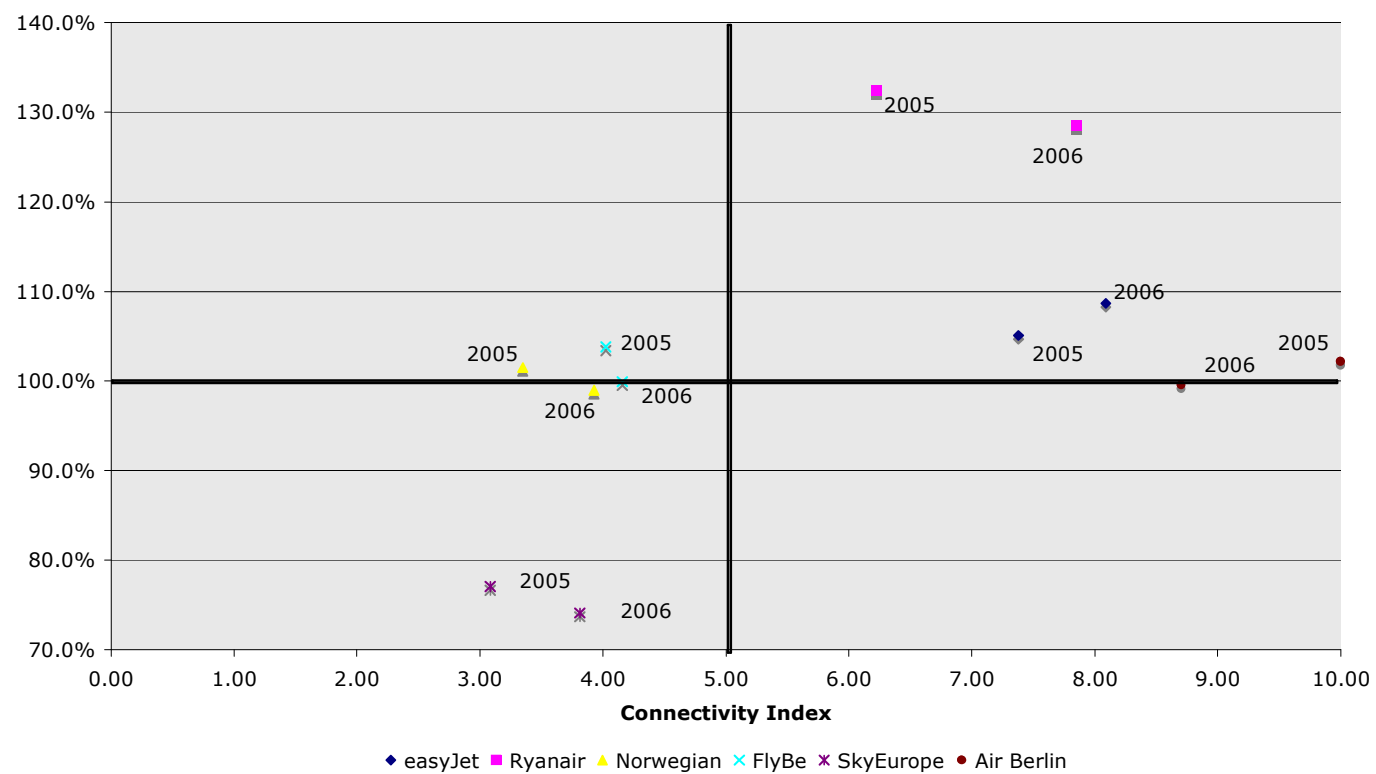

- easyJet $\approx$ Ryanair $\triangle$ Norwegian $\times$ FlyBe $*$ SkyEurope $\bullet$ Air Berlin 
Figure 6: Cost Index and Comfort Index

Cost Index and Comfort Index

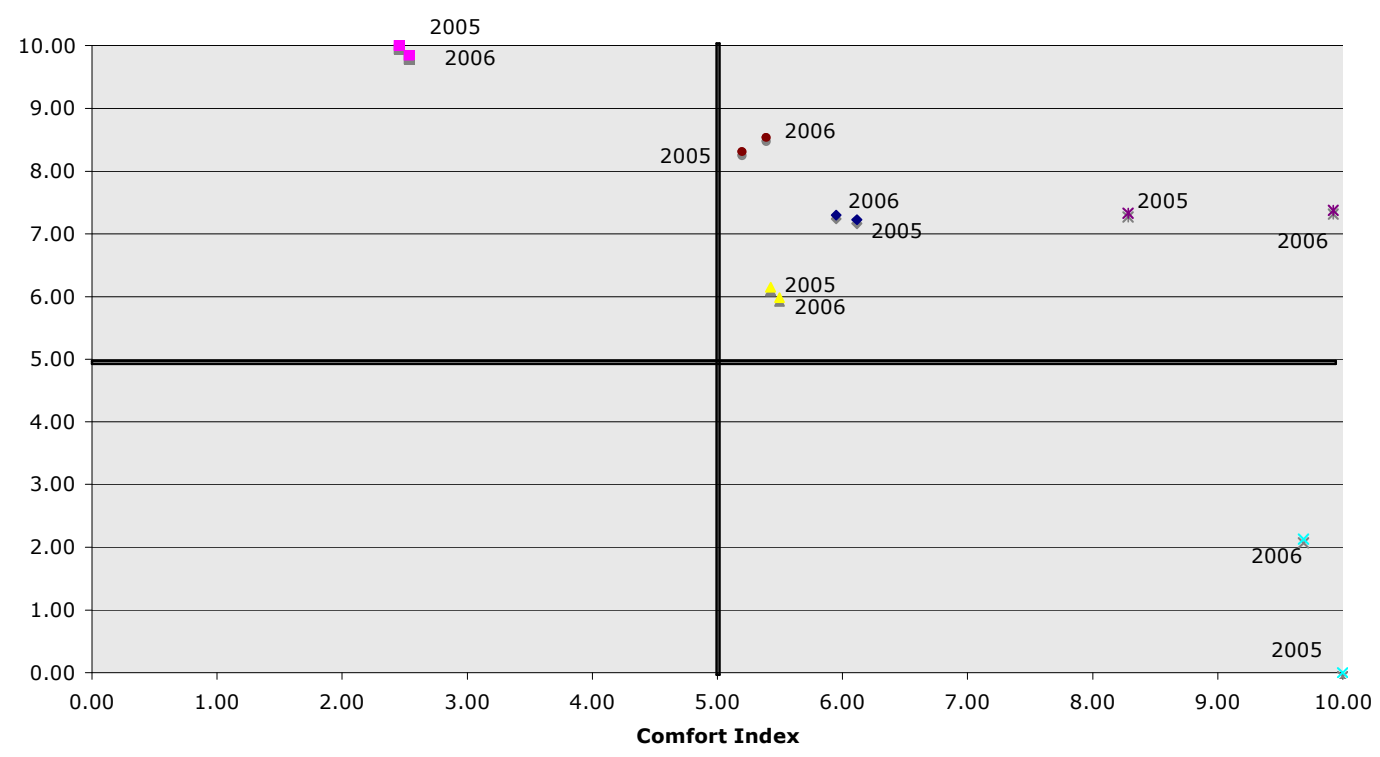

- easyjet $₫$ Ryanair $\triangle$ Norwegian $\times$ FlyBe $*$ SkyEurope - Air Berlin 
Figure 7: Operating Profit and Sector Length

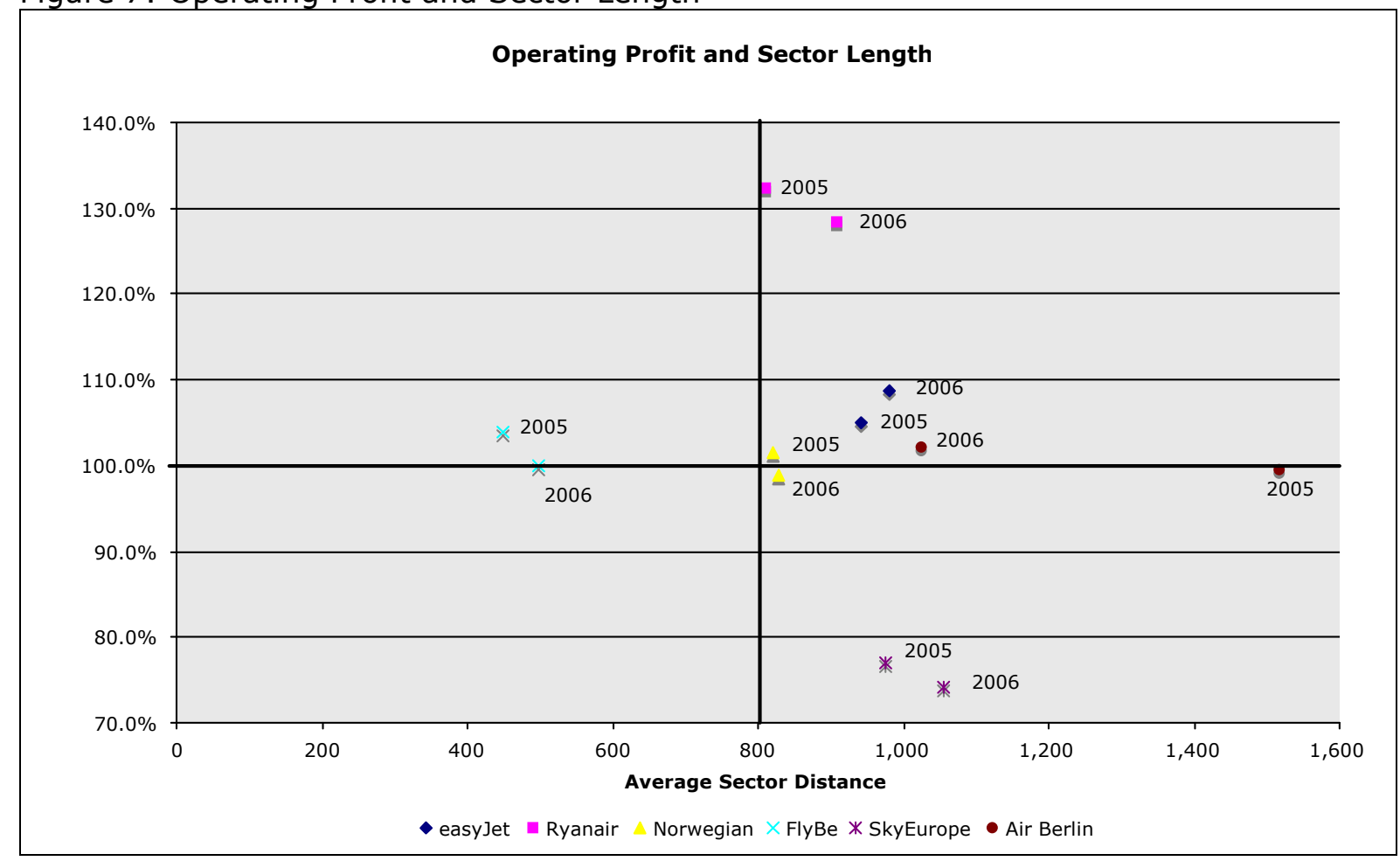


Figure 8: Operating Ratio and Sectors per day

Operating Ratio and Sectors per day

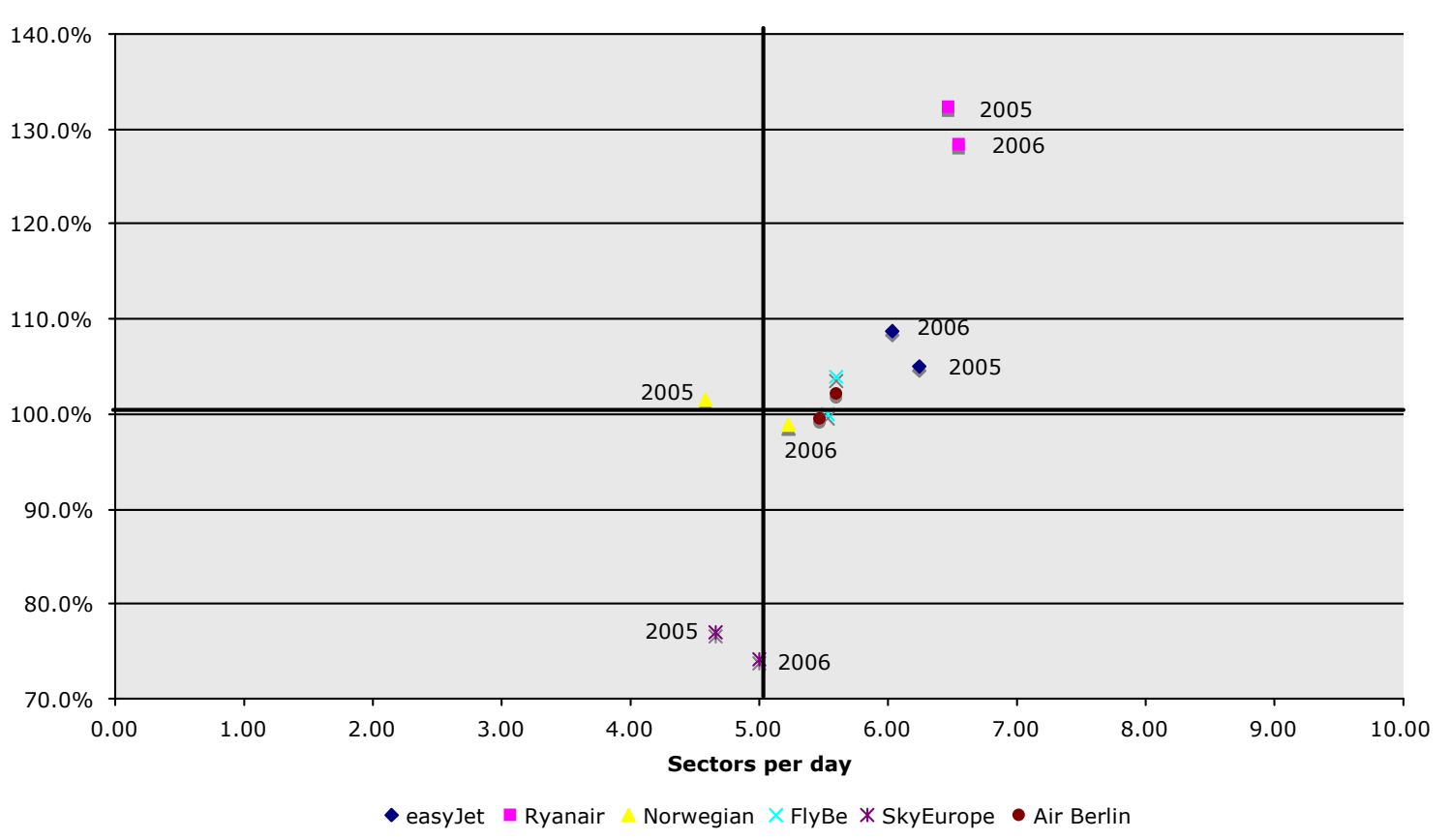

